\author{
Berit Hansson ${ }^{1}$, Suzanna Lundblad ${ }^{1,4}$, JS \\ Torgerson $^{2}, \mathrm{AK}$ Lindroos $^{3}$ and Trevor \\ Archer $^{4 *}$ \\ ${ }^{1}$ Sahlgrenska University Hospital, Gothenburg, \\ Sweden \\ ${ }^{2}$ Norra Älvsborgs Länssjukhus, Trollhättan, Sweden \\ ${ }^{3}$ MRC Human Nutrition Research, Cambridge, UK \\ ${ }^{4}$ University of Gothenburg, Department of \\ Psychology, Box 500, SE 40530 Gothenburg, Sweden \\ Dates: Received: 26 April, 2016; Accepted: 05 May, \\ 2016; Published: 06 May, 2016 \\ *Corresponding author: Trevor Archer, University \\ of Gothenburg, Department of Psychology, Box \\ 500, SE 40530 Gothenburg, Sweden, E-mail: \\ trevor.archer@psy.gu.se \\ www.peertechz.com \\ ISSN: 2455-5460 \\ Keywords: Anorexia nervosa; Obesity; Alexithymia; \\ Psychopathological features; Psychological health
}

\author{
Research Article
}

\section{Anorexia Nervosa and Obesity: A Psychological Health Comparison}

\section{Introduction}

Patients presenting anorexia nervosa (AN) and those presenting obesity (OB) express marked differences in bodily appearance and shape, but these eating disorder patients, nevertheless, share several common features. Although in some quarters the presence of $\mathrm{OB}$ as an eating disorder may be denied, for the purposes of the present study and based on our own psychiatric convictions $\mathrm{OB}$ is regarded as a disorder with eating behavioral consequences. Both groups show markedly problems, symptomatically, with food intake and eating behaviour. This patient group is occupied also, in a variety of ways, with persistent thoughts concerning what to eat or not, the number of calories in-taken, slimming techniques and other related topics. Both groups of eating disorder patients are afflicted with poor physical health and accompanying complaints. Several studies have shown a U-or J-shaped relationship between Body Mass Index (BMI) and mortality, with individuals at the extremely low and the extremely high weight levels at increased risk for serious health problems (National Task Force on Prevention and Treatment of Obesity, Overweight, Obesity and [1]. Eating disorders imply critical threats to personal safety and constitute a growing problem, and seems to be overrepresented in adults with neuropsychiatric disorders compared with the general population [2-4], with links to childhood adversity [5,6]. Anorexia nervosa constitutes a psychiatric disorder with a prolonged course, severe medical and psychiatric morbidity, and often a severe extent of co-morbidity [7] and high levels of mortality. Obesity is not considered a psychiatric disorder, but rather a medical disorder with psychopathological eating behavior since it is not associated with consistent and adaptive behaviors and psychopathological features. It is well known, however, that women suffering from obesity often present psychological symptoms, such as anxiety and depressive symptoms [8-10].

Patients presenting eating, or eating-type, disorders often report alexithymia, an inability to identify and describe their emotions and affective status $[11,12]$. They show a paucity of words expressing feelings and demonstrate difficulties in identifying and distinguishing feeling of physical sensations. Alexithymia and personal distress seem to predict the vulnerability features of Anorexia Nervosa (AN) with higher levels of personal distress in the latter linked to poor selfregulation and emotional awareness [13]. There is a high co-morbidity between the eating disorders (Lundblad et al., 2003), AN and OB, and anxiety and/or alexithymia disorders [14], moreover, AN patients display certain features similar to those abusing substances/exercise, through a 'narrowed' behavioral repertoire such that weight loss, food intake restriction, and excessive exercise interfere with other activities in a similar fashion to substance/exercise abuse [15]. Further, comorbidity between AN, anxiety, depression and psychoactive substance use has been described [16]. It is likely that the disorder elevates anxiety, depression with stress presenting a predisposing factor to poorer health-related quality-of-life and social support [17]. The core affective processes that evolve into the development and maintenance of eating disorder remain relatively unknown although the contributions of alexithymia suggest an affective basis [18].

The purpose of the present study was to compare the psychopathological features of women diagnosed with either AN or OB using well-established instruments that included Minnesota Multiphasic Personality Inventory-2 (MMPI-2), Toronto Alexithymia Scale (TAS-20), Beck Depression Inventory (BDI), the Symptom Checklist-90 (SCL-90) with accompanying Eating Disorder Inventory (EDI-2) and the Global Assessment of Functioning Scale (GAF).

\section{Method and Materials}

\section{Participants}

The patient sample consisted of six women presenting AN [19], and with a BMI range of 14.3-14.9, who were consecutively assessed at Sahlgrenska University Hospital, at a special psychiatric clinic for 
adult eating disorder patients and six women presenting $\mathrm{OB}$ [20], and with a BMI range of 42.0-58.7, who were assessed consecutively at the Department of Body Composition and Metabolism at the same hospital.

\section{Instruments}

The Minnesota Multiphasic Personality Inventory - MMPI-2: The MMPI-2 is a structured personality test that assesses degree of psychopathology in terms of 10 different dimensions; hypochondrias, depression, hysteria, psychopathic deviate, masculinity-femininity, paranoia, psycho-asthenia, schizophrenia, mania and social introversion. The test is a true-false self-report questionnaire consisting of 567 statements. The responses of each individual tested are assumed to reflect that person's conscious self- image. The test mainly consists of clinical scales and validity scales. The validity scales measure test-taking attitude and assess whether the individual being tested took a normal, honest approach to the test. These scales allow us to see whether the subject is feigning his/her responses in any way. The test-retest reliability of MMPI- 2 ranges from 0.58 to 0.91 for women. More information about the test is given in Butcher and Williams's book from 1992 [21].

The 20 item Toronto Alexithymia Scale - TAS-20: The TAS20 , which is considered the best existing measure of alexithymia, has demonstrated good reliability and validity. Alexithymia involves difficulties in identifying and describing emotions. The three central factors of TAS-20 are:

1. "difficulty identifying feelings",

2. "difficulty in describing feelings to others", and

3. "externally-oriented thinking" [22].

Each TAS-20 item was rated on a 5-point Likert scale with total scores ranging from 20-100. The cut-off point for alexithymia is $\geq 61$, which has been empirically established [23].

The Symptom Check List (SCL-90): The SCL-90 is a self-report instrument designed to assess general psychopathology. It contains 90 items, distributed over nine subscales, which are labelled somatization, obsession-compulsion, interpersonal sensitivity, depression, anxiety, hostility, phobic anxiety, paranoid ideation and psychoticism [24]. The SCL-90 has been widely used all over the world [25] and has been shown to have a good validity and reliability [26].

The Beck Depression Inventory (BDI): Level of depression was assessed using the 21-item Beck Depression Inventory (BDI) and the factors of BDI are dependency, self-criticism and efficacy. BDI is a self-report instrument as well and has good validity and reliability [27].

The Eating Disorder Inventory (EDI): The EDI is a self-report instrument widely used in studying eating disorders. The Swedish version of EDI-2 (Garner, 1991; Garner \& Norring, 1994) includes 91 items distributed over eleven different scales: drive for thinness, bulimia, body dissatisfaction, ineffectiveness, perfectionism, interpersonal distrust, interoceptive awareness, maturity fears, ascetism, impulse regulation and social insecurity.
The Global Assessment of Functioning (GAF): Today, most patients who are referred to the psychiatric care system are being routinely assessed with the DSM system [19]. The Global Assessment of Functioning (GAF), is a numeric scale (0 through 100) used by clinicians to subjectively rate the social, occupational and psychological overall level of functioning of adults.

A non-parametric test (The Wilcoxon-Mann-Whitney test) was used to analyse for differences between the $\mathrm{AN}$ and $\mathrm{OB}$ groups of patients.

\section{Ethical statement}

The research ethics committee at Sahlgrenska University Hospital, Göteborg Sweden, approved the present study. Patient's consent (informed consent) was obtained from the patients. All the patients were informed that study results would be subjected to data analysis with the purpose of writing and publishing a research report.

\section{Results}

AN patients showed evidence of psychopathological symptoms than OB patients. The former expressed significantly higher levels of alexithymia (TAS score $=66$ ) than the latter (TAS score $=48, \mathrm{p}<0.05$ ), combined with significantly lower levels of global functioning (GAF score $=30)$ compared the OB patients $($ GAF score $=57.5, \mathrm{p}<0.01)$. The general psychopathological problems include ineffectiveness, perfectionism, interpersonal distrust, interoceptive awareness, maturity fears, extreme abstemiousness, lack of impulse regulation and social insecurity. Furthermore, the AN patients (EDI-psych = $58, \mathrm{p}<0.05)$ obtained higher scores on the EDI-psychopathology scale than the OB patients (EDI-psych $=19.5)$ but did not differ on the EDI-symptom scales. The AN patients $(\mathrm{EDI}-3=11, \mathrm{p}<0.05)$ obtained lower scores on the EDI-3 scale than the OB patients (EDI$3=20.5$ ), but higher scores on the EDI-5, EDI- 6 and EDI-7 scales (Tables 1,2). The EDI-3 scale refers to "body dissatisfaction" whereas the EDI-5, EDI-6 and EDI-7 refer to "perfectionism", "interpersonal distrust" and "interoceptive awareness", respectively.

\section{Discussion}

Individuals presenting $\mathrm{AN}$ and those presenting $\mathrm{OB}$ display marked problems in the management of food intake and eating behaviors. Nevertheless, $\mathrm{AN}$, as distinct from $\mathrm{OB}$, reflects one form of eating disorder as well as a psychiatric disorder according to ICD10 and Axis 1 in DSM-1V. The ICD-10 defines obesity as a medical condition, expressed in eating disorder rather than a psychiatric

Table 1: Comparisons between AN .and OB patients on the TAS, BDI, SCL and GAF instruments.

\begin{tabular}{|c|c|c|c|c|c|c|c|c|}
\hline & \multicolumn{3}{|c|}{ Anorexia nervosa } & \multicolumn{4}{c|}{ Obesity } & p-value \\
\hline & Median & Min. & Max. & & Median & Min. & Max. & \\
\hline TAS & $66^{*}$ & 57 & 77 & 48 & 45 & 69 & 0.045 \\
\hline BDI & 23.5 & 12 & 42 & & 18 & 1 & 40 & 0.38 \\
\hline SCL & 144.5 & 24 & 199 & 95.5 & 9 & 150 & 0.2 \\
\hline GAF & $30^{* *}$ & 20 & 40 & & 57.5 & 50 & 70 & 0.0036 \\
\hline
\end{tabular}

${ }^{\star *} \mathrm{p}<0.01,{ }^{\star} \mathrm{p}<0.05$, Wilcoxon-Mann-Whitney $\mathrm{U}$ tests. 
Table 2: Comparisons between $\mathrm{AN}$.and $\mathrm{OB}$ patients on the EDI-psych, EDIsymp and EDI-1 to EDI-11 scales.

\begin{tabular}{|c|c|c|c|c|c|c|c|}
\hline & \multicolumn{3}{|c|}{ Anorexia nervosa } & \multicolumn{3}{|c|}{ Obesity } & \multirow[t]{2}{*}{ p-value } \\
\hline & Median & Min. & Max. & Median & Min. & Max. & \\
\hline EDI-psych & $58^{*}$ & 17 & 104 & 19.5 & 6 & 52 & 0.03 \\
\hline EDI-symp & 21.5 & 12 & 37 & 27 & 15 & 53 & 0.47 \\
\hline EDI-1 & 9.5 & 2 & 18 & 7.5 & 2 & 16 & 0.51 \\
\hline EDI-2 & 1 & 0 & 9 & 1 & 0 & 10 & 0.79 \\
\hline EDI-3 & $11^{*}$ & 2 & 16 & 20.5 & 7 & 27 & 0.03 \\
\hline EDI-4 & 12 & 3 & 20 & 7.5 & 0 & 16 & 0.29 \\
\hline EDI-5 & $7^{\star}$ & 2 & 11 & 0.5 & 0 & 10 & 0.05 \\
\hline EDI-6 & $4.5^{\star}$ & 2 & 8 & 1.5 & 0 & 7 & 0.05 \\
\hline EDI-7 & $13^{*}$ & 1 & 19 & 2 & 0 & 10 & 0.04 \\
\hline EDI-8 & 5 & 1 & 11 & 1.5 & 0 & 8 & 0.08 \\
\hline EDI-9 & 4.5 & 0 & 16 & 3.5 & 1 & 5 & 0.41 \\
\hline EDI-10 & 2.5 & 0 & 10 & 0 & 0 & 5 & 0.15 \\
\hline EDI-11 & 7 & 3 & 16 & 4 & 0 & 7 & 0.08 \\
\hline
\end{tabular}

${ }^{*} \mathrm{p}<0.05$, Wilcoxon-Mann-Whitney $\mathrm{U}$ tests.

disorder. In consideration of the background, it is interesting to observe that both groups in the present study scored high on the EDI2 sub-scales for eating disorder symptoms and that no significant differences were found between the groups. The instrument EDI-2 was designed to assess eating disorders rather than obesity. Eating behaviour is subject to influences of a multitude of affect-modulating conditions in which individuals develop personal attributes and acquire attitudes and habits that may be life-long, unless altered by circumstance; the affective component of eating disorder and AN, in particular, has been shown [28]. AN patients expressed higher levels of "perfectionism", "interpersonal distrust" and "interoceptive awareness", respectively, compared to OB patients; these attributes appear to contribute to the psychopathological symptom profiles of AN. Contrastingly, OB patients expressed higher levels of "body dissatisfaction" which implies that they were aware that some selfalteration of their obese condition was a necessity from several health perspectives. As a measure aimed at facilitation of psychological and physical health, it would appear more appropriate to rescind control needs regarding food intake and eating behaviour than to abstain drastically from intake of necessary nutrients. The observation that body and weight concerns predicted AN diagnosis [28], implies that cognitive-emotions or selective attentional processes may either contribute to or bolster the disorder. Certainly, any need for control and a specific body shape and weight may in turn motivate dietary restraint and an operationalization into behavioural strategies and dietary rules that can either be successful (resulting in weight loss) or fail in implementation (subjective or objective binge eating episodes) arising, e.g. from failure to abide by dietary rules [29]. Normal social life, positive feelings and interest in other individuals is usually absent AN patients with a BMI $>15$ [30]. AN patients display impairments in several aspects of social cognition [31,32], with specific regard to social signals reflecting emotional states of those in their proximity $[33,34]$ and an exaggerated tendency to observe body rather than eyes [35].

In the present study, AN patients expressed higher levels of alexithymic symptoms than the OB patients. It was observed previously [28] that AN patients expressed high levels of "Emotional identifying", "Emotional describing", "Emotional orientation" and Total scoring on the TAS instrument concomitant with low levels of positive affect and higher levels of restraint, eating concern, shape concern, weight concern, higher global score on the EDI-2 and higher levels of negative affect. It was found also that the AN condition was predicted by three factors shape concern and weight concern whereas positive affect was counter-predictive [28]. In another previous study observing a different group of patients [36], it was indicated that AN patients displayed higher levels of negative affect and negative emotions, more stress and depression, greater sleeping problems, pain, and use of analgesic drugs and mood-enhancing drugs, together with lower levels of positive affect and positive emotions but higher levels of physical activity. Regression analysis indicated that the diagnosed AN condition was predicted by negative affect, sleeping problems, use of mood-enhancing drugs exercise frequency. It was concluded that excessive exercise combined with depression, anxiety, obsessivecompulsive and addictive behaviors and sleep problems rendered AN representative from a perspective of multiple co-morbidities, possibly exacerbated through recurring bouts of starvation diets. It is possible also that those individuals who are unequipped to retain affective balance, through the pressures of childhood adversity, under conditions of emotional upheaval remain at risk for development of AN [37].

\section{Limitations}

Although the number of patients participating in the present study was small $(n=6)$, the statistical significances obtained with these result point towards some rather robust differences in psychopathology as expressed by AN and OB patients. Suffice it to say, the present findings are in agreement with those obtained previously with different samples of the patient groups.

\section{Acknowledgments}

The Sahlgrenska Foundation's Research and Development Fund provided financial support for this study.

\section{References}

1. National Task Force on prevention and Treatment of Obesity (2000) Overweight, obesity and health risks. Arch Intern Med 106: 898-904.

2. Karjalainen L, Gillberg C, Råstam M, Wentz E (2016) Eating disorders and eating pathology in young adult and adult patients with ESSENCE. Compr Psychiatry 66: 79-86.

3. Mustelin L, Latvala A, Raevuori A, Rose RJ, Kaprio J, et al. (2016) Risky drinking behaviors among women with eating disorders-A longitudinal community-based study. Int J Eat Disord. 2016

4. Rosling A, Salonen Ros H, Swenne I (2016) One-year outcome and incidence of anorexia nervosa and restrictive eating disorders among adolescent girls treated as out-patients in a family-based setting. Ups J Med Sci 121: 50-59.

5. Björkenstam E, Burström B, Vinnerljung B, Kosidou K (2016) Childhood adversity and psychiatric disorder in young adulthood: An analysis of 107,704 Swedes. J Psychiatr Res 77: 67-75.

6. Su X, Liang H, Yuan W, Olsen J, Cnattingius S, et al. (2016) Prenatal and early life stress and risk of eating disorders in adolescent girls and young women. Eur Child Adolesc Psychiatry 2016.

7. Goldstein RB, Chou SP, Saha TD, Smith SM, Jung J, et al. (2016) The epidemiology of antisocial behavioral syndromes in adulthood: results from the National Epidemiologic Survey on Alcohol and Related Conditions-III. J Clin Psychiatry. 
8. Altman D, Iliadou AN, Lundholm C, Milsom I, Pedersen NL (2016) Somatic comorbidity in women with overactive bladder syndrome. J Urol pii: S00225347(16)00353-0.

9. Birmingham CL, Beumont PJV (2004) Medical Management of Eating Disorders. Cambridge, Cambridge University Press.

10. Jakuszkowiak-Wojten K, Landowski J, Wiglusz MS, Cubała WJ (2015) Impulsivity in anxiety disorders. A critical review. Psychiatr Danub 27 S452455 .

11. Courty A, Godart N, Lalanne C, Berthoz S (2015) Alexithymia, a compounding factor for eating and social avoidance symptoms in anorexia nervosa. Compr Psychiatry 56: 217-28.

12. Guillén V, Santos B, Muñoz P, Fernández de Corres B, Fernández E, et al (2014) Toronto alexithymia scale for patients with eating disorder: [corrected] performance using the non-parametric item response theory. Compr Psychiatry 55: 1285-1291.

13. Beadle JN, Paradiso S, Brumm M, Voss M, Halmi K, et al. (2015) Large hippocampus size in women with anorexia nervosa who exercise excessively than healthy women. Psychiatry Res 232: 193-199.

14. Brand-Gothelf A, Leor S, Apter A, Fennig S (2014) The impact of comorbid depressive and anxiety disorders on severity of anorexia nervosa in adolescent girls. J Nerv Ment Dis 202: 759-762.

15. Barbarich-Marsteller NC, Foltin RW, Walsh BT (2011) Does anorexia nervosa resemble an addiction? Curr Drug Abuse Rev 4: 197-200.

16. Jordan J, Joyce PR, Carter FA, Horn J, McIntosh VV, et al. (2003) Anxiety and psychoactive substance use disorder comorbidity in anorexia nervosa or depression. Int J Eat Disord 34: 211-219.

17. Nekouei ZK, Doost HT, Yousefy A, Manshaee G, Sadeghei M (2014) The relationship of alexithymia with anxiety-depression-stress, quality of life, and social support in coronary heart disease (A Psychological Model). J Educ Health Promot 23: 68.

18. Lundblad S, Hansson B, Archer T (2014) Affect-group intervention for alexithymia in eating disorders. Int J Emerg Ment Heal Hum Resourc 17: 219223.

19. American Psychiatric Association (1994) Diagnostic and Statistical Manual of Mental Disorders-DSM-IV. Fourth Edition. Washington, D.C., Author.

20. International Statistical Classification of Diseases and Related Health Problems (1995) Tenth Revision (ICD-10), WHO.

21. Butcher JN, Williams CL (1992) Essentials of MMPI2 and MMPIA Interpretation Minneapolis: University of Minnesota press.

22. Bagby RM, Parker JDA, Taylor GJ (1994) The twenty-item Toronto Alexithymia Scale - I: item selection and cross-validation of the factor structure. J Psychosom Res 38: 23-32.
23. Taylor GJ, Bagby RM, Parker JDA (1997) Disorders of Affect Regulation Cambridge, Cambridge University Press.

24. Derogatis LR (1977) Symptom Check List-90 manual. Baltimore: John. Hopkins University Press.

25. Derogatis LR (1977) SCL-90-R, Symptom Checklist -90-R National Computer System Inc., MN 55440, USA.

26. Vassend O, Lian L, Andersen TH (1992) Norske versjonenr av NEOPersonality Inventory, Symtom CheckList 90, Revised, og Giessen Subjective Complants List. Tidskrift för Norsk Psykologförening 29: 1150-1160.

27. Beck AT, Ward CH, Mendelson M, Mock J, Erbaugh J (1961) An inventory for measuring depression. Arch Gen Psychiatry 4: 561-571.

28. Lundblad S, Magnusson J, Hansson B, Archer T (2015a) Cognitive-affective status in anorexia nervosa: self-image and absence of positive emotions. Clinical and Experimental Psychology.

29. Gianini L, Liu Y, Wang Y, Attia E, Walsh BT, et al. (2015) Abnormal eating behavior in video-recorded meals in anorexia nervosa. Eat Behav 19: 28-32.

30. Seidel M, Petermann J, Diestel S, Ritschel F, Boehm I, et al. (2016) A naturalistic examination of negative affect and disorder-related rumination in anorexia nervosa. Eur Child Adolesc Psychiatry.

31. Caglar-Nazali HP, Corfield F, Cardi V, Ambwani S, Leppanen J, et al. (2014) A systematic review and meta-analysis of 'Systems for Social Processes' in eating disorders. Neurosci Biobehav Rev 42: 55-92.

32. Zucker NL, Losh M, Bulik CM, Labar KS, Piven J, et al. (2007) Anorexia nervosa and autism spectrum disorders: guided investigation of social cognitive endophenotypes. Psychol Bull 133: 976-1006.

33. Cserjesi R, Vermuelen N, Lenard L, Luminet O (2011) Reduced capacity in automatic processing of facial expression in restrictive anorexia nervosa and obesity. Psychiatry Res 188, 253-257.

34. Zhu Y, Hu X, Wang J, Chen J, Guo Q, et al. (2012) Processing of food, body, and emotional stimuli in anorexia nervosa: a systematic review and metaanalysis of functional magnetic resonance studies. Eur Eat Disord Rev 20: 439-450.

35. Watson KK, Werling DM, Zucker NL, Platt ML (2010) Altered social reward and attention in anorexia nervosa. Front Psychol 1: 36.

36. Lundblad S, Garcia D, Hansson B, Archer T (2015b) Emotional well-being in anorexia nervosa: negative affect, sleeping problems, use of mood-enhncing drugs and exercise frequency. Arch Depress Anxiety 1: 1-5.

37. Toyokawa S, Uddin M, Koenen KC, Galea S (2012) How does the social environment 'get into the mind'? Epigenetics at the intersection of social and psychiatric epidemiology. Soc Sci Med 7: 67-74.

Copyright: (c) 2016 Hansson B, et al. This is an open-access article distributed under the terms of the Creative Commons Attribution License, which permits unrestricted use, distribution, and reproduction in any medium, provided the original author and source are credited. 